\title{
On BE Vocabulary Teaching Embarrassments and Its Strategy
}

\author{
Lin Yuan \\ Zhejiang Gongshang University, Hangzhou, China \\ Email: bonyyuan@163.com
}

\begin{abstract}
Vocabulary is considered a vital core in learning a language. As the cornerstone of language acquisition, vocabulary acquisition exerts direct influence on language competence and sociability. So it is with Business English teaching. However, due to the specific features of BE lexis, China' BE teachers and learners are faced with spectacular embarrassments. This paper analyzes the present situation and makes proposals to improve it.
\end{abstract}

Index Terms - Business English, vocabulary teaching, embarrassments, strategy

\section{INTRODUCTION}

\section{A. Business English}

Business English, to be exact, is then English for Business. The terminology "BE" is rather a vague concept with diversified Chinese names.

$\mathrm{BE}$ is firstly English, and $\mathrm{BE}$ is not a special variety of English, different in kind from other forms. Certainly there are some features which can be identified as typical of a particular context of use. BE looks out to the general public and inwards to a particular business. It resembles GE in one way, but it also contains many words and phrases strange to the laymen. However besides language competence, BE is completed by a combination of business professional knowledge, communication skills, cross-cultural awareness and management skills.

I prefer to define $\mathrm{BE}$ as a dynamic and open concept, with its content constantly enlarging, expanding and developing. Facing the challenges brought by the economic globalization and China's entry into the WTO, educators of BE must correspondingly shift their mode of concepts and thinking, and align the teaching objectives with the needs of the modern society and their local condition, so as to cultivate a contingent of integrative talents who not only have a good command of English but also master the fundamentals of business. The modern society needs a diversified contingent of integrative talents. This is the inevitable trend of specific education.

\section{B. BE Vocabulary Features}

BE should not and could not repel all language phenomena. It should not repel phonetics, pragmatics, semantics, grammar, rhetoric, discourse, though they are not them. But due to its technical specification, BE has its design features in style, syntax and lexis. BE lexis features are summarized into the following five aspects.

(1) Many BE expressions are coined with GE (General English) ordinary vocabulary, but make specific and technical sense. The superficial understanding will surely mislead learners. For example:

If a country is exporting more than it imports, it is receiving foreign currency and has a balance of trade surplus.

"balance" in GE means "apparatus for weighing, esp. with scale at each end of beam supported by central pivot" or "counteracting weight or force". In the above sentence, "balance" technically means "difference in value between exports and imports". See more examples:

You have a credit balance of $£ 250$.

Unable to be authorized further credits from the bank, the company is driven to bankruptcy.

If we see the expression as "a man of credit", we will respond with least hesitation and understand it as "a credible and respectable man". But in the previous two example sentences, we see "credit" no longer means "belief or confidence", but refers to "a sum of money advanced or loaned by a bank.". And "balance" refers to "remained amount between savings and expenditures".

(2) In BE, some words are rare and complicated, but they are professional and idiomatic.

a) Foreign trade contracts are typical of adopting old English that are out of use in modern English. They are usually compounded adverbs by adding one or more prepositions to "here", "there", "where" and the like, such as hereby, whereof, thereabout.

b) A lot of uncommonly-used words are used in BE. Most of these can be substituted with ordinary words in GE which are shorter and more readable. However, if these rare words are replaced by common words, the text style may be harmed. for example, the choice of "extraneous $\sim$ external from outside" is listed from the rare to the common.

(3) Frequent use of abbreviations 
a) In telex and telegraph, words are shortened and capitalized according to practice for the sake of economy and efficiency, which look more like signals.

YR TLX 28 TH RCVE.

b) As e-mail popularizes, telex and telegraph are gradually replaced. Initialisms are commonly found in BE expressions. Such as DM ---direct mailing, DFS ---duty-free stores

(4) Fixed terms belonging to a certain industry or business cannot be replaced readily. The existing jargons or neology have formed on the basis of average acceptance, so alternative way to express them will make you a layman or confuse others, though the alternative is grammatically logical and semantically similar.

(5) Numeric Expressions.

It will never be too precise in BE expressions. In BE, random use of unit words will leave a loophole to cause later loss or trouble. Take measurement system for example. American system adopts short ton (0.9072 metric ton), while British system adopts long ton (1.0161 metric ton). "ton" is ambiguous in BE expression. Time indications should tally with what is stated in agreement without least difference or least room for misunderstanding. The seemingly-trifle preposition plays a vital role. "To be shipped before Dec.5.", and "To be shipped on or before Dec. 5." are of different dispatch conditions.

\section{BE VocABUlary TEACHING EMBARRASSMENTS}

Many factors play a role in BE vocabulary acquisition, though the exact nature of the role is not always clearly understood and the findings of some research studies seem to contradict what has been standard or ideal practice in BE classroom. Some factors are to do with input, in other words the way in which BE vocabulary presents itself. Other factors are to do with mental process when it is needed to recall or retrieve BE vocabulary. These factors have been considered key and beneficial to GE acquisition, however, in the present BE teaching, these pose embarrassments of BE teaching.

\section{A. Input Factors}

\section{(1) Frequency}

BE beginners' ambition is hit by an abrupt turn. They are depressed to find that familiar words suddenly become odd and they are unable to catch the implication of the expressions even with every word known. Seemingly, they are reduced from intermediate learners to $\mathrm{ABC}$ beginners.

BE beginners' courses are usually arranged by content of business conducts rather than by grammatical or semantic gradation of difficulty. Each unit focuses on one special subject. Words related to the subject do not necessarily repeat in another topic, though they are all under the jurisdiction of BE. And the beginning unit isn't surly primary enough for BE beginners to cope with.

(2) Materials

China's BE education is carried out as required or optional courses, lasting at least one semester with students who take it out of general or vague idea. Prior to a course, seldom will teachers meet students to investigate and analyze their needs. Secondly, Unlike a seminar or a training center, there is rare chance for college BE teachers to group students of identical or similar needs and basic training level together and teach on a case-by-case basis. Lastly, material writing is such a time and money-consuming business. Academically qualified as some teachers are, not all can afford the cost.

Therefore, we usually adopt ready-published materials. In most cases, this choice is made on the basis of teachers' capability rather than that of students, or even sometimes by sponsors out of commercial purpose.

(3) Contextualization

The disparity in GE meaning is due to grammatical structure while the specific concept in BE are confined to the scope it describes. When teaching lexis, we cannot input a comprehensive concept of the word without input of necessary background information. In BE, so many words are so diversified in various scopes and express abstract concepts. It is impossible for teachers to master all and put across a systematic but hyper-general business world to students, which may distract students from word to business.

\section{B. Mental Process}

(1) Depth of processing

Cognitive psychologists have suggested that learners are more likely to remember a word if they have worked on its meaning actively. In other words, a depth of process will aid mental retention.

Students are prone to retention of concrete words, which are easily related to daily life. Enhanced GE vocabulary library can push negative inference or transfer to BE memory. Besides, BE words, esp. terms are mostly abstract concepts to pre-experienced BE learners. Except in reading and paper test, students seldom come into contact with such concepts initiatively. Lack of application in real communication causes the word memory to fade fast.

(2) Word network

Intermediate BE learners have built a vocabulary library mentally. When mentioning "laugh", they will recall " smile", "giggle", "chuckle", " beam" and so many to describe the meaning shadows. A particular word will gradually 
expand into part of a semantic cluster. In GE teaching, teachers are making use of learners' systematical networks of meaning to facilitate word memory.

Since intermediate GE learners are still BE beginners, their BE vocabulary library is right in process of scaffolding. As we all know, not until the connection of Internet can computer display incredible power besides its primary computing capacity. Where to start pre-experienced BE learners' vocabulary scaffolding and how to build associations for abstract BE words deserve careful consideration.

(3) Cultural factors

When we teachers conduct BE teaching to intermediate learners, we are facing a new task to achieve integration of language, culture and business in one single curriculum. It is a reflection of market orientation of foreign language teaching. In the past decade of GE learning, learners are imparted with much information about the history, geography, political and economic systems, customs, etc. of the target language country ( mainly the USA and the UK). That is informational culture. In this way, students are cultivated a sense of which the worldwide native speakers of English have about the American and the British culture.

When they are involved in BE learning, achievement culture and behavioral culture must be emphasized more. Hammerly (1982) describes achievement as "artistic and literary accomplishment". An achievement culture is one where people work hard to achieve goals and better the group as a whole. Behavioral culture is "actual behavior plus attitudes, values, etc", including "conversational formulas and kinesics." (Hammerly, 1982). The interpretation of achievement and behavioral culture may be too elusive for academic research purpose, but "conversation formulas and kinesics" and "accomplishment" are the forms of culture most important to real communication. By grasping these, the students will understand the nature of intercultural business communication skills and be able to operate effectively in an intercultural business environment.

The language proficiency gives learners the advantage of easy adaptation to a foreign culture and the business knowledge grants them the power to handle business affairs, and cultural competence in the cross-cultural business communication aids them to take off quickly in business circle.

Business world is a borderless world, which means that communicating with other multiple cultures besides American or British ones is not a luxury, but a necessity. There have been numerous theoretical models of cultural differences and practical guide books and course books based on the research on cross-cultural communications. Normal ways for teachers to introduce the relative cultures are comparison between the target culture and mother culture, oral explanation to a certain language point, illustration by figures or games and so on. Multi-media equipment brings more three dimensional presentations of foreign cultures. However, the armchair strategy is not impressive enough for students to integrate the theoretical input into their actual behavior. Without being involved personally involved, students won't have chance to refer to a prototype.

Another problem is that business communication touches upon so many regional cultures. This requires more roundabout multi-cultural awareness and knowledge of BE teachers and high sensitivity and tolerance of cultural differences and flexibility in dealing with the differences. All these are better accomplished in actual practice outside classrooms.

\section{Vocabulary TEACHING StRATEGy}

The traditional grammar-translation method had prevailed for quite a long time, and right now many business-oriented language teaching still adopts this method. In BE teaching, G-T method mostly suits students' established model of language learning but it produces more desirable results in written tests than in real business communication. Focusing on full cognitive development, I propose to expand BE vocabulary from the following aspects.

\section{A. Expanding from Comparison}

\section{Comparison in Meanings}

In BE vocabulary teaching, teachers can present a word with its antonyms at the same time. It is more efficient to present licencee with licencer, proceeds with expenses than to present separate words.

It is easily found that the so-called antonyms in BE are more in the complementary or conversive sense. The denial of one means the assertion of the other or vice versa or there is an interdependence of meaning, which implies that one member of the pair presupposes the other member. Thus, they are not simply contraries. The concepts are related closely. Students won't thoroughly catch the isolated sense of one without idea of the other. By presenting them in line can help students remain the unity of opposites simultaneously. Students save the trouble of explaining isolated concepts one by one and students are building up their BE vocabulary domains step by step.

2. Comparison in Word Formation

Conciseness and accuracy will be of primary importance in BE, which is reflected on modification parts well. Complex phrases or sentences with more than one attributive modifications are rare. Highly-compact compounding is preferred in $\mathrm{BE}$. And $\mathrm{N}+\mathrm{N}$ structures are syntactic tendency.

Such expressions as product line, or marketing mix are not actually new to students, for they have learned almost every single word in GE. However, the reformation and adaptation causes confusion. By comparing with those 
expressions in GE style, students catch the core with ease. And this comparison is exerting potential influence on students' awareness of BE word formation. Gradually, they can derive such original and accepted expressions by making use of what they have acquired in GE, students will be more creative in thinking for their own, more capable in expressing themselves comprehensively and more readily receptive to new idea.

3. Comparison in Collocations

Two linguistic items that occur together frequently are collocations. Collocations are institutionalized, fixed and non-compositionalized. Institutionalization means a collocation is conventionalized in a language. Fixedness means that a collocation is frozen as a sequence of words. And non-compositionality means the global meaning of a collocation cannot be interpreted by its component words. These three criteria operate together and present in different degrees in each collocation.

$\mathrm{BE}$ professionals have intuition of collocation knowledge from their practical experience, but it is quite problematic for pre-experienced BE learners. Pre-experienced BE learners tend to translate BE collocations out of Chinese literal equivalents intuitively rather than out of its essential business implications. And moreover, their GE knowledge may bring about adversarial interference.

Psycholinguists discover that language is processed, and often acquired in chunks of words, rather than a word-by-word basis. The important thing is to enable students to realize that each language register has its own collocations. Practice overweighs grammar here.

In fact, collocations have specialized meanings, which are different from the meanings of their head words. BE collocations have their stylistic constraints. Most of BE collocations are rare and non-substitutable. The properties of BE collocations challenge learners' confidence in using. Even if learners have a nodding acquaintance with a certain collocation, the fixedness in the form and the pragmatic specifications of the idiom may prevent learners from proper production.

The table above lists some possible alternatives occurring to BE learners. When given the Chinese translation of those collocations, BE learners can soon find familiar synonyms or informal words in GE to express the sense and make grammatically-logical collocations. By distinguishing the deviation from the original meaning, students will comprehend the uniqueness of the BE collocations. Specific and purposeful matching exercises can keep them on the alert for subtle switch of meaning, which is just the prudence required in real business communication.

There is another type of BE collocations prone to causing confusion among pre-experienced BE learners, for those collocations are professional definitions or contain specific implication. Not all can understand open policy or sea protest without second thinking.

The obscure or opaque definitions are abstract and complex, and experience in business will help a lot in acquiring the essential sense of them. As to pre-experienced BE learners, the explanation of one single concept may involve a chain of more complex and systematic introduction to be pre-informed as a premise. So it will be wiser for teachers to accompany students to the large gap between the BE collocations and their corresponding confusing expressions or misunderstanding on the basis of passing on certain business knowledge, which will not go beyond students' head too much to puzzle or bore them. Since the linkage between a multi-word unit and its headword is quite loose, if not absent, students surely need much independent efforts to enhance the comprehension.

4. Comparison in Word Specification

As mentioned above, BE has many rare words in use to meet its formal style. However, much classroom behavior is set within taken-for-granted frameworks of expectations, attitudes, values and beliefs. Facing the BE learners who have grasped a good command of GE but nearly zero command of BE, teachers should lay stress on BE word specification extremely so as not to train students as non-professionals.

Certainly, we do not encourage students to choose rare or unfathomable words to show off their sophistication, but we guide them to spot the right word on the right occasion.

Traditional straight translation or rote learning are proved "easy come and easy go". Words can neither be long retained nor correctly used because students are passively pushed to facing the isolated concepts. By comparison in differential aspects of BE vocabulary with those of GE, students participate personally in the discovery trip. Teachers are like guides who lead students to the spots along and give cues occasionally, and students themselves sense the beauty or hardship at their own pace. Potentially students will one day become backpackers who are capable of an independent trip or even guides.

\section{B. Expanding from the Incidental}

Language learning is to a large extent incidental. You can learn a language incidentally, while you are actually thinking about something else. (Hutchinson, 1987, p.129) This indirect teaching of vocabulary assumes that vocabulary expansion will happen through the practice of other language skills, which has been proved not enough to ensure vocabulary expansion.

$\mathrm{BE}$ has its specification together with mass popular penetration into everyday life. Consciously or not, more or less everyone touches upon BE, let alone BE learners, by watching TV, reading magazines, walking on the streets and so on. The important thing for BE teachers is to organize students' unconscious bits and pieces in BE pickup into conscious acquisition. 
Brands are flashing around our lives. And currently English branding is in fashion. BE learners should not only be sensitive to the brand names or brand marks, but also to their commercial intentions and cultural connotations by understanding the language well. Brands have been so far used mainly for identification. A well-organized brand makes its offering "sure" things in market. "Ivory Soap" under P\&G, "Ace Hardware", and "Midas Muffler" are good models. "Ivory" implies the $99.44 \%$ pureness of the soap. "Ace" suggests "excellent and outstanding". And by quoting the name "Midas"--- a legendary king who was said to touch a stone and turn it into gold, we easily think of the muffler as a magic tool.

After certain accumulation, a mini-seminar can be held to clarify and enhance students' incidental pickup in bits and pieces. BE teachers encourage learners to observe, to question and to air opinions. BE learners should taste the ingenious tactics in the language use and ponder over the problems and solutions. Of course, brands won't be the only topic. Commercial phenomena can be all brought into issue. In this way, we cultivate students' business sensitivity and flexibility and oblige the learners to use language and thereby to fix the language into the matrix of knowledge in their minds. We can expect a more international commercialization in China due to a better qualified generation of $\mathrm{BE}$ learners.

\section{Expanding from the Perceptual}

University BE learners are mostly pre-experienced in actual business despite their proficient language competence. Classroom teaching equips them with theoretical knowledge awaiting test in practice. That is to say, students' perceptual cognition must be consolidated into rational system.

Chinese students are very likely to confuse "company" with "corporation". When asked about the differences between the two words, we usually get the following explanations:

1) In British English, people prefer "company"; in American English, people prefer "corporation".

2) A corporation is a large company.

3) They actually mean the same and are exchangeable.

The confusion or taken-for-granted frameworks are partly due to the messy English translated name of organizations of China. And even in dictionaries or textbooks, students find various translated English versions at will, such as

the People's Insurance Company of China;

China Ocean Shipping Company;

China National Foreign Trade Transportation Corporation;

International Trust Investment Corporation of China

From the above English versions, we don't see any particularity in choosing the word "company" or "corporation".

The word "company" or "corporation" has been used in China with the introduction of legal form of western enterprises. However, the two words are still being used separately in the laws of the U.S. and the U.K.

According to the Oxford Companion to Law, company is "an association of a number of persons for a common purposes, frequently for the carrying on of a business with a view to profit, and a mode or organization suitable for association too large to operate as partnerships...". In current British law, company excludes the ownership of partnership which is included in Chinese company law. According to the same law, "Corporation: a group of individuals, or a series of the holders of an office, who are deemed in law to be a single legal entity. A corporation is accordingly sometimes called an artificial or juristic or corporate person, as distinct from a natural person."

Things go opposite in America. According to Black's Law Dictionary, "company: union or association of person for carrying on a commercial or industrial enterprise; a partnership, corporation, association, joint stock company." Company is too broad a definition to Americans. Then "corporation: an artificial person or legal entity created by or under the authority of a state or nation, composed, in some rare instance, of a single person and his successors, being the incumbents of a particular office, but ordinary consisting of an association of numerous individuals"( Roberts. W, 1999, p.25). The definition is essentially similar to that of the British one, but American corporation has more categories such as private corporation, public corporation, Eleemosynary corporation and professional corporation.

The above analysis exhort us to be cautious of the deeper implication behind rather than be mislead by the superficial phenomenon. Even a single BE word can contain strict legal regulations, learners with ignorance about the point will fail to meet the challenge both from language and from professions.

To expand students cognition from the perceptual to the rational is a long and tortuous course. We are impossible and inadequate to tell all the truth, but we should spare no efforts to drive students to meticulous thoughts.

\section{IMPLICATIONS FOR BE VOCABULARY TEACHING}

The traditional focus of BE vocabulary learning for Chinese college students has been on the expansion of BE vocabulary size, which is often meaning driven. Typically, BE learners are encouraged to get a vocabulary as large as possible and they are proud of knowing one particular sense of a BE word. However, our study revealed that, even for primary BE expressions that have been considered common sense to business professional and that are generated from so simple GE words, BE learners' lexical competence is far from proficient. In the current BE teaching in China, more attention is drawn from vocabulary size to vocabulary depth. BE teachers should be made aware of the various levels 
and dimensions of BE vocabulary knowledge so that the insights of academic research can find their way into the everyday educational practice. The present study brings us some implications for BE teaching.

Above all, attention to the core of BE should be spotted on BE lexis. As an American saying goes, "We are friends because of differences." GE and BE are a pair of friends, who supplement each other. BE not only caters to professional requirements but also faces the public. It thus in one way resembles GE, but it also contains many words and phrases unknown to the layperson. These distinctions are more to do with lexis and less to do with grammar.

Since BE never goes against the principles of English language, it is wise to exert efforts on the uniqueness of BE--its lexis. Due to its distinct features, BE lexical teaching pattern needs adaptation from that of GE. GE vocabulary teaching centers on the grammatical patterns while the lexical patterns are virtually untouched. Most GE learners therefore copy the lexical patterns of the Chinese corresponding words into those of English words. Sometimes, teachers may be uncertain about some lexical items because of the lack of the native instinct to judge the properness. That imposes a hindrance. With a decade of such GE learning experience, BE learners continue to follow the convention--- they copy the lexical patterns of the corresponding GE words into those of BE words. Those patterns often look stilted, if not totally wrong in business context.

So we should remain the authentic exposure of BE to learners. What BE learners need most is not the recognition of isolated new words but the nativelike and professional mastery of BE words. Concordances from BE corpora, such as Key Words in Business (Mascull,1996) can serve as good texts to cultivate BE learners' insight into the specification of $\mathrm{BE}$ lexis. The occurrence of certain partner in the corpora demonstrates whether the pattern is acceptable in a most natural BE environment. In addition, typical mistakes or avoidance in the corpora can foretell what will be likely to happen among learners. In this way, teachers can come up with more needs and effective instructions.

Secondly, a rule learning of fixed collocations is suggested in BE teaching. Many of the phrasal verbs, nouns which one feels one does not have to learn, or learns with little effort are very frequent in GE. However, the recombination of them brings about confusion among learners. In GE, students get accustomed to moving gradually from isolated words into phrases. In BE, students are encouraged to make full and extended use of known words on a recombination basis. BE beginners should learn common collocations, phrasal verbs in particular, as single lexical items. Then they are supposed to find rules in the BE language through frequent application of the chunks. The assumption is that by finding rules one also find restrictions on use and generate new patterns by unpacking their chunks. Rote learning and the construction of rules interact and actively feed into each other.

Finally, BE output is held to be of super importance. Though students always stumble over words in production, they are not really challenged. Unlike GE proficiency which is measured mainly in receptive tests for academic purposes, BE is tested in actual business practice. Knowing what BE professionals do renders more confidence and reference to BE learners than marking a correct choice in a paper test. "Production will aid acquisition only when learner is pushed" (Ellis, 1994, p.282). "Pushing" learners beyond their current performance level can lead to enhanced performance, which may ensure the internalization of $\mathrm{BE}$ acquisition or the consolidation of existing competence. BE teachers should push students to an open business environment rather than restrain teaching in a closed classroom. Even a virtual task or presumed occasion can aid learners to move from the semantic processing prevalent in comprehensions to the communicative processing needed for production.

Sometimes, without the innovation of BE testing, teachings' efforts in raising students' consciousness to real production end in vain. To ensure a successful output-oriented vocabulary teaching, a corresponding change in the vocabulary testing is urgently called for. A yes/no test won't help much. BE should be tested in macro aspect. Unlike micro test items as Vocabulary and Grammar in CET Band Four and Six, BE test items should manifest more of learners' in-depth vocabulary knowledge and generactivity. BEC can be a reference model for BE test carried out at university level. The test should achieve a balance among validity, reliability and practicability.

\section{REFERENCES}

[1] Aitchison, J. (1994). Words in the mind: An introduction to the mental lexicon (2nd edition). Oxford: Blackwell.

[2] Carter, R. (1987). Is there a core vocabulary? Some implications for language teaching. Applied Linguistics 8: 178-193.

[3] Hector Hammerly. (1982). Synthesis in second language teaching: an introduction to linguistics. Second Language Publications.

[4] Hutchinson, Tom and Alan Waters. (1987). English for Specific Purpose NP: Cambridge University Press.

[5] Leech, G. (2011). The role of frequency in ELT: New corpus evidence brings a re-appraisal. Foreign Language Teaching and Research, Issue 1 Vol 4, 3-20.

[6] Lewis, M. (1997a). Pedagogical implications of the lexical approach. In J. Coady \& T. Huckin (Eds.). Second language acquisition (pp. 255-270). Cambridge: Cambridge University Press.

[7] Lewis, M. (1997b). Implementing the lexical approach. Hove: Language Teaching Publications.

[8] Nation, P. (1990). Teaching and learning vocabulary. New York: Newbury House.

[9] Liu Fagong, Nan zuomin, (1998), Contemporary International Business English, Chongqing: Chongqing Publishing House.

Lin Yuan was born in Nanchang, China in 1977. She received her Master degree in applied linguistics from Zhejiang Gongshang University, China in 2006. 
She is currently a lecturer in the School of Foreign Languages, Zhejiang Gongshang University, Hangzhou, China. Her research interests include intercultural communications and Business English. 